\title{
Borderline personality disorder and bias in the recognition of facial expressions of emotion: a pathway to understand the psychopathology
}

\author{
Gabriela C. S. Ferreira1, Rafael Faria Sanches ${ }^{1}$, José Alexandre de Souza Crippa1,2, Marcelo Feijó de Mello³, \\ FLÁVIA L. OSÓRIO1,2
}

1 Department of Neurosciences and Behavior, Ribeirão Preto Medical School, University of São Paulo (FMRP-USP), Ribeirão Preto, SP, Brazil.

2 National Institute of Science and Technology - Translational Medicine, Ribeirão Preto, SP, Brazil.

3 Department of Psychiatry, Federal University of São Paulo (Unifesp), São Paulo, SP, Brazil.

Received: 10/4/2017 - Accepted: 2/6/2018

DOl: 10.1590/0101-60830000000146

\begin{abstract}
Background: The identification of facial emotions is a key skill as it promotes rapid and accurate recognition of emotions and enables better communication and greater social adaptation. More recent studies have suggested that impaired social interactions may be related to deficits in social cognition and therefore in the recognition of facial expressions, contributing to social disturbance among individuals with borderline personality disorder (BPD). Objective: To present the results of an empirical study assessing the recognition of facial emotion expressions in women with BPD, having as reference a group of healthy women from the general population. Methods: The subjects ( 40 female with BPD and 40 controls) were assessed with a dynamic task on a computer screen for recognition of facial expressions of emotion. Results: The BPD group had a lower accuracy in perceiving emotions of fear and surprise and slowness in recognising happiness. Logistic regression analyses also identified an association between BPD and higher sensitivity in the recognition of anger. Discussion: Women with BPD made more mistakes in the recognition of negative emotions, which can bias the behaviour and regulation of affective states, favouring in turn the emergence of some typical symptoms associated with BPD.
\end{abstract}

Ferreira GCS et al. / Arch Clin Psychiatry. 2018;45(1):7-11

Keywords: Face, emotion, borderline, personality, psychopathology.

\section{Introduction}

Borderline personality disorder (BPD) is characterised by experiences of great affective intensity and distinct impairment of emotion regulation, thus resulting in affective instability, especially within the social context ${ }^{1,2}$. Studies have recently suggested that this impairment in social interactions may be related to social cognition deficits, which consequently affects the recognition of facial expressions of emotion and contributes to social problems among individuals with BPD ${ }^{3-5}$.

Some studies report minor impairments in BPD patients. Von Ceumern-Lindenstjerna ${ }^{6}$ showed images of facial expressions to female adolescents diagnosed with BPD and to health ones, including those with other psychiatric diagnoses. The subjects were asked to name the emotion shown on each image and estimate the intensity of negativity and pleasantness in the face. The adolescents with BPD showed no deficit in naming the emotions, not differing from the other groups. Nevertheless, the adolescents with BPD perceived positive facial expressions of emotion with less intensity and pleasantness, but perceived negative facial expressions with more intensity and negativity.

A literature review conducted by Domes et al. ${ }^{4}$ showed that individuals with BPD who performed emotion recognition tasks presented alterations, such as subtle deficits in recognising basic emotions and response bias (i.e. attributing negativity or anger to the face), including increased sensitivity in detecting negative feelings. In this sense, the authors hypothesised that there must be an emotional hyper-activity in these patients which interferes with their cognitive processing of facial emotions.

Similarly, a study conducted by Unoka et al. 7 demonstrated that BPD patients were less accurate than controls in the emotional recognition tasks, mainly in discriminating negative emotions. These patients also attributed excessive feelings of disgust, fear and surprise to the faces. On the other hand, these patients presented no impairment in the recognition of happiness facial expressions.

Corroborating these data, a meta-analysis on the issue showed that subjects with BPD had a lower rate of hits in the recognition of negative emotions compared to controls, mainly regarding anger and disgust. However, they poorly performed in the identification of neutral faces as they attributed erroneously emotions to them ${ }^{8}$.

Another interesting aspect regarding studies on facial recognition and BPD has to do with changes observed in neuroimaging examinations. Within this context, it was found that patients with $\mathrm{BPD}$ had an increase in the activation of amygdala when they were shown images inducing adverse emotions or with human faces expressing feelings. It should be highlighted that amygdala is known to be the main structure involved in the processing of anxiety and other emotional states, in addition to being associated with BPD because of specific alterations 9,10 .

These findings indicate that deficits in facial recognition of emotional expressions can favour biases in behaviour and regulation of affective states, favouring in turn the emergence of some typical symptoms associated with BPD, such as impulsivity, self-aggression and hetero-aggression, and contributing to unstable social relationships ${ }^{4}$. Therefore, it is clinically relevant to know this dimension regarding mainly control and treatment of the picture.

Considering this whole context, the results of an empirical study carried out in Brazil will be presented with the objective of assessing the recognition of facial expressions of emotion in BPD women, having as reference a group of healthy women from the general population.

\section{Methods}

\section{Subjects}

The sample consisted of two distinct groups consisting each of 40 adult women matched by socio-demographic characteristics. The subjects of BPD group were recruited from private and public psychiatric outpatient clinics and met DSM-IV criteria for BPD ${ }^{1}$. The control group consisted of students and staff of an education institution and of a primary healthcare program, and users of a nongovernmental organisation, with no history of previous diagnosis 
or psychiatric treatment. The psychiatric condition assessment was performed by using the Structured Clinical Interview based on the DSM-IV (SCID-IV) ${ }^{11,12}$. Exclusion criteria for both groups were the following: lack of signature of the informed consent form and incomplete filling-up of the questionnaire.

\section{Instruments}

The following instruments were used to characterise the sample:

A. Clinical and sociodemographic questionnaire;

B. Structured and Clinical Interview for DSM-IV11,12;

C. Beck Anxiety Inventory (BAI) - developed by Beck et al. ${ }^{13}$, translated into Brazilian Portuguese, adapted, and validated for the Brazilian population by Cunha ${ }^{14}$;

D. Patient Health Questionnaire (PHQ-9) - developed by Spitzer et al. ${ }^{15}$, translated into Brazilian Portuguese and validated for the Brazilian population by de Lima Osório et al. ${ }^{16}$;

E. Fast Alcohol Screening Test (FAST) - developed by Hodgson et al. ${ }^{17}$, translated into Brazilian Portuguese and validated for the Brazilian population by Menezes-Gaya et al.18;

F. Fagerström's Nicotine Dependence (FTND) - developed by Heatherton et al. ${ }^{19}$, translated into Brazilian Portuguese and validated for the Brazilian population by Carmo and Pueyo ${ }^{20}$;

G. Facial expression recognition task - computerised task consisting in a series of 24 photos of actors expressing typical characteristics of six basic emotions (i.e. happiness, sadness, fear, disgust, anger and surprise) are presented to the subjects for recognition. The stimuli used were those described by Ekman and Friesen ${ }^{21}$ and the procedure was that standardised by Arrais et al.22. In such a procedure, photographs with four different white actors (i.e. two men and two women) representing the six basic emotions were selected. Images of each emotion were submitted to the morphing technique and then grouped, resulting in a video clip starting with a neutral face (no emotion) and ending with a typical representation of the emotion in question (full emotion). The video clips were shown on a touch screen by using the Superlad 4.0 software (Cedrus Corporation $^{\circledR}$ ). For analysis, accuracy was regarded as primary variable ( $1=$ hit; $0=$ error) and response time (seconds) and emotional intensity for recognition (0\%-100\%) were regarded as secondary variables.

\section{Data collection and analysis}

The present study was conducted according to the ethical human research code and approved by the Local Ethics Committee (HCRP Process n. 2316/2011).
Data were individually collected and inserted in a database. To analyze the data, we used: a) descriptive statistics: analysis of the sociodemographic and clinical features of the sample; b) Z-score test for two population proportions (Bonferroni's correction, Chi-square test, Student's t-test and covariance analyses: comparison groups;) Multivariate logistic regression (backward method) in which the outcome variable was $B P D$. The variables whose $p$ value was below 0.20 in the univariate analyses were included in the initial logistic regression model ${ }^{23}$.

It was adopted a significance level of $\mathrm{p}<0.05$

\section{Results}

Socio-demographic and clinical characterisation of the groups can be seen in Table 1.

According to Table 1, the groups are homogeneous regarding age and education level, but differing in the clinical characteristics, with BPD group presenting more indicators of psychopathology (comorbidity) and greater functional impairment (72.5\% unemployed). In the BPD group, $100 \%$ were undergoing psychiatric treatment, $50 \%$ had at least one lifetime psychiatric hospitalization, and $85 \%$ reported at least one suicide attempt. With regard to medications used, the main ones were: selective serotonin re-uptake inhibitors, mood stabilisers, benzodiazepines, neuroleptics and tricyclic antidepressants, most of them used jointly.

The rates of hits/accuracy in facial emotion recognition are listed in Table 2, with only differences being found in the emotions of fear and surprise. The BPD group had significantly more mistakes in recognising such feelings compared to the control group. When indicators of depression, anxiety and substance abuse (confounding variables) were included as co-variables, the significant differences between the groups were maintained $(p<0.05)$. By analysing the incorrect responses, no specific bias was observed between the groups $(\mathrm{p}>0.05)$.

Table 3 shows data regarding the response time in the task of facial emotion recognition in which the only statistically significant difference between the groups was found for emotion of happiness, although the response time was longer for all emotions in the BPD group.

Table 4 shows the results regarding the emotional intensity required in the task of facial emotion recognition by using the morphing technique. BPD group required more emotional intensity to identify all the basic emotions, regardless of the face gender. However, there was statistically significant difference only in the emotion of happiness.

Table 5 shows data regarding the final model of logistic regression analysis for identification of the most significant associations between $\mathrm{BPD}$ and recognition of facial expressions of emotions.

Table 1. Socio-demographic and clinical characteristics of the sample

\begin{tabular}{|c|c|c|c|c|c|c|}
\hline \multicolumn{2}{|l|}{ Variables } & \multicolumn{2}{|c|}{$\begin{array}{c}\mathrm{BPD}(\mathrm{N}=40) \\
\mathrm{N} \%\end{array}$} & \multicolumn{2}{|c|}{$\begin{array}{c}\mathrm{C}(\mathrm{N}=40) \\
\mathrm{N} \%\end{array}$} & \multirow{2}{*}{$\begin{array}{l}\text { Statistics } \\
\qquad p=1.00\end{array}$} \\
\hline Education level & $\begin{array}{l}\leq 9 \text { years } \\
>9 \text { years }\end{array}$ & $\begin{array}{l}22 \\
18\end{array}$ & $\begin{array}{l}55.5 \\
45.0\end{array}$ & $\begin{array}{l}22 \\
18\end{array}$ & $\begin{array}{l}55.5 \\
45.0\end{array}$ & \\
\hline Marital status & \begin{tabular}{|l|} 
Single/divorced \\
Married
\end{tabular} & $\begin{array}{l}25 \\
15\end{array}$ & $\begin{array}{l}62.5 \\
37.5\end{array}$ & $\begin{array}{l}22 \\
18\end{array}$ & $\begin{array}{l}55.0 \\
45.0\end{array}$ & $p=0.49$ \\
\hline Employment status & $\begin{array}{l}\text { Unemployed } \\
\text { Employed }\end{array}$ & $\begin{array}{l}29 \\
11\end{array}$ & $\begin{array}{l}72.5 \\
27.5 \\
\end{array}$ & $\begin{array}{c}9 \\
31\end{array}$ & $\begin{array}{l}22.5 \\
77.5\end{array}$ & $p<0.001^{*}$ \\
\hline Children & Mean (SD) & 1.0 & (1.3) & 1.1 & (1.6) & $p=0.88$ \\
\hline Age & Mean (SD) & 35.7 & $(10.5)$ & 35.4 & (11.0) & $p=0.91$ \\
\hline Depression Score & Mean (SD) & 19.22 & (6.4) & 7.77 & (6.76) & $p<0.001^{*}$ \\
\hline Anxiety Score & Mean (SD) & 33.35 & (14.19) & 9.92 & $(10.73)$ & $p<0.001^{*}$ \\
\hline Alcohol Score & Mean (SD) & 2.27 & (3.48) & 1.76 & (2.5) & $p<0.001^{*}$ \\
\hline Tobacco Score & Mean (SD) & 4.42 & (3.05) & 0.58 & (1.6) & $p<0.001^{*}$ \\
\hline
\end{tabular}


Table 2. Accuracy in the facial emotion recognition task

\begin{tabular}{|l|c|c|c|}
\hline Emotion & $\begin{array}{c}\text { BPD (N=40) } \\
\text { Mean (SD)/Rate Hits }\end{array}$ & $\begin{array}{c}\text { C (N=40) } \\
\text { Mean (SD)/Rate Hits }\end{array}$ & $p=0.19$ \\
\hline Happiness & $3.72(0.78) / 93.0 \%$ & $3.90(0.30) / 97.5 \%$ & $p=0.57$ \\
\hline Sadness & $3.07(0.91) / 76.8 \%$ & $2.95(1.06) / 73.8 \%$ & $p=0.04^{*}$ \\
\hline Fear & $1.85(1.07) / 46.3 \%$ & $2.32(1.02) / 58.0 \%$ & $p=0.73$ \\
\hline Disgust & $2.77(1.07) / 69.3 \%$ & $2.85(0.89) / 71.3 \%$ & $p=0.16$ \\
\hline Anger & $2.85(1.14) / 71.3 \%$ & $2.52(0.90) / 63.0 \%$ & $p=0.01^{*}$ \\
\hline Surprise & $2,67(1.24) / 66.8 \%$ & $3.30(0.88) / 82.5 \%$ & $p=0.21$ \\
\hline Female face & $8.10(2.51) / 67.50 \%$ & $8.67(1.50) / 72.25 \%$ & $p=0.24$ \\
\hline Male face & $8.85(2.31) / 73.8 \%$ & $9.17(1.41) / 76.4 \%$ & $p=0.45$ \\
\hline
\end{tabular}

SD: standard deviation; p. significance level; BPD: group of borderline personality disorder; C: control group. * Statistic significance.

Table 3. Response time (seconds) in the facial emotion recognition task

\begin{tabular}{|l|c|c|c|}
\hline Emotion & $\begin{array}{c}\text { BPD (N = 40) } \\
\text { Mean (SD) }\end{array}$ & S (N=40) & $p=0.03^{*}$ \\
\hline Happiness & $9.89(3.81)$ & $8.86(5.38)$ & $p=0.16$ \\
\hline Sadness & $12.44(4.82)$ & $11.06(3.78)$ & $p=0.37$ \\
\hline Fear & $11.59(4.30)$ & $10.78(3.61)$ & $p=0.07$ \\
\hline Disgust & $12.54(4.57)$ & $10.87(3.63)$ & $p=0.70$ \\
\hline Anger & $12.66(3.68)$ & $12.27(5.16)$ & $p=0.08$ \\
\hline Surprise & $12.26(5.20)$ & $10.59(3.07)$ & $p=0.24$ \\
\hline Female & $11.43(3.70)$ & $10.46(3.65)$ & $p=0.15$ \\
\hline Male & $11.16(3.79)$ & $10.01(3.28)$ & $p=0.18$ \\
\hline Total & $11.77(3.96)$ & $10.65(3.47)$ & \\
\hline
\end{tabular}

SD: standard deviation; $p$ : significance level; BPD: group of borderline personality disorder subjects; C: control group. * Statistic significance.

Table 4. Emotional intensity (percentage) required in the task of facial emotion recognition

\begin{tabular}{|l|c|c|c|}
\hline Emotion & $\begin{array}{c}\text { BPD (N=40) } \\
\text { Mean (SD) }\end{array}$ & S (N=40) & $p=0.01^{*}$ \\
\hline Happiness & $85.96(17.92)$ & $73.98(22.0)$ & $p=0.88$ \\
\hline Sadness & $95.10(14.66)$ & $89.72(13.13)$ & $p=0.23$ \\
\hline Fear & $93.14(14.23)$ & $89.09(15.90)$ & $p=0.15$ \\
\hline Disgust & $95.12(14.86)$ & $90.58(13.23)$ & $p=0.23$ \\
\hline Anger & $96.29(13.78)$ & $92.74(12.88)$ & $p=0.80$ \\
\hline Surprise & $91.05(18.06)$ & $90.14(14.98)$ & $p=0.08$ \\
\hline Female & $93.93(14.66)$ & $87.89(16.41)$ & $p=0.07$ \\
\hline Male & $93.15(15.18)$ & $87.01(15.67)$ & $p=0.08$ \\
\hline Total & $94.83(14.13)$ & $89.18(14.94)$ & \\
\hline
\end{tabular}

SD: standard deviation; p: significance level; BPD: group of borderline personality disorder subjects; C: control group. * Statistic significance.

Table 5. Final model of multivariate logistic regression analysis

\begin{tabular}{|l|c|c|c|c|c|c|}
\hline Variables & B & SD & P & OR & \multicolumn{2}{|c|}{$95 \% \mathrm{Cl}$} \\
\cline { 3 - 7 } & & & & 0.05 & 0.61 & 0.38 \\
\hline Fear (rate of hits) & -0.48 & 0.25 & 0.03 & 1.79 & 1.06 & 3.00 \\
\hline Anger (rate of hits) & 0.58 & 0.27 & 0.01 & 0.48 & 0.28 & 0.80 \\
\hline Surprise (rate of hits) & -0.73 & 0.26 & & \\
\hline
\end{tabular}

B: beta value; SE: standard error; P. significance level; OR: odds ratio; Cl: confidence interval.

The logistic regression analysis identified an association between BPD and higher sensitivity in the recognition of anger and low accuracy in the recognition of fear and surprise.

\section{Discussion}

Nowadays, it is considered that processing, recognition and expression of emotions are not just innate phenomena which invoke genetic memories in order to allow humans to react to the environment on an adaptive basis, as proposed by Darwin ${ }^{24}$. With the development of cerebral cortex over the evolution of the human species, it is suggested that this phenomenon also occurs at some level with mediation of learning, cognitive resources and cultural values $^{25}$. In view of this, several studies have been investigating particularities of the facial emotion recognition in a variety of contexts to understand this complex phenomenon ${ }^{26,27}$.

In the field of mental health, alterations in the facial emotion recognition were evidenced in several psychopathologies characterised by impairments in both recognition tasks and emotion processing, with abnormal activation of various cerebral areas ${ }^{28,29}$. Specifically in relation to $\mathrm{BPD}$, changes in the emotional recognition can be attributed to the deregulation of emotions, personality traits, 
cognitive impulsivity, aggressiveness, alterations in specific brain structures, among other damages, which can impact the socialcognitive functioning 4 .

Previous studies on the issue showed evidence on some of the main impairments in $\mathrm{BPD}$, such as presence of negative bias to ambiguous and neutral stimuli, increase in the sensitivity on recognising emotions of fear and anger, impairment in the recognition of basic emotions, emotional hyper-activity, and functional and structural changes in the brain 4,30,31.

With regard to the alterations demonstrated in the present study, one of them was the recognition of fear (low rate of hits). The adaptive value of this emotion is in the anticipation of the danger as the feeling of fear activates protective and avoidant behaviours to any person, animal, idea or event seeming dangerous and which may cause physical and psychological damage. Fear may occur in response to immediate or upcoming situations, and experiencing it may be sometimes as bad as the real damage itself. Therefore, identifying the emotion of fear in the people's face may indicate the presence of threats nearby, thus mobilising the individual to prompt action to couple with danger ${ }^{27,32}$.

The poor recognition of fear is corroborated by previous studies, and a possible hypothesis explaining this deficit has to do with functional changes in limbic structures and anterior regions of the brain. These regions are related to, respectively, degree of subjectively experienced negative events and regulation of emotions ${ }^{33}$. In the limbic system, amygdala plays an important role in fear conditioning, control of aggressiveness, emotional memory and fight-or-flight response.

Another hypothesis explaining the deficit in fear recognition can be supported by Wagner and Linehan ${ }^{34}$, who stated that the emotional dysregulation observed in BPD patients can also be evidenced in terms of deficits (hyper-activity), which facilitates the lack of emotional reaction in view of some environmental stimuli with affective valence. On the other hand, according to the same authors, the perception of fear in the other can increase the one's own experience of fear as there is an association between perceiving emotions in the other and activation of the one's own physiological arousal. This would compromise the individual's ability to handle with the other's feelings (empathy) and to fit to the environmental stressors and dangers, thus making them vulnerable.

Similar changes were found in the recognition of the emotion of surprise. This feeling is characterised for being the briefest of all emotions, lasting only a few seconds at the most. Almost everything can provoke surprise because of the fact that this emotion is elicited by unexpected situations, comments, opinions, gestures and events. Nevertheless, as soon as what had surprised us is identified, this emotion transforms into another feeling, such as fear, happiness or anger. Fear is the most commonly emotion following a surprise, perhaps because unexpected events are often interpreted as a threat. In this sense, fear and surprise are frequently misunderstood in the recognition of these emotions, since there are even facial similarities in their expressions ${ }^{27,32}$.

In the recognition of surprise, the BPD group also made significantly more mistakes compared to the control group. The greatest difficulty in recognising such an emotion is partially corroborated by related studies as it is not specifically a negative feeling and whose recognition is reportedly impaired in BPD patients.

Among the six basic emotions, anger is perhaps the most highlighted in the BPD as such a feeling is one of the most experienced by individuals with the disorder and has been mostly reported in studies using facial emotion recognition tasks, thus being frequently related to biases, less or more hits and hyper-reactivity in its detection 4,31,34,35.

Anger may be one of the most dangerous emotions. There are several causes for this feeling, such as being rejected, cheated or expectations not met. Depending on the individual's personal history, even small frustrations can elicit anger. Experiencing anger, in part, involves the risk of losing control and thus it is important to recognise this emotion, mainly in the other person by predicting aggression, insult or rejection so that one can defend against them ${ }^{26,32}$.

Although our study has not found any statistical difference between the groups regarding anger-related variables, it should be emphasised that the logistic regression analysis showed that this emotion was one of the strongest factors associated with BPD. Hypothetically, these patients are more skilled in detecting anger as a way of predicting rejection or threat, which can be reflected by an increase in the emotional response involving limbic system and amygdala. This response pattern can contribute to the conflicting relationships often reported by BPD patients ${ }^{4}$.

With regard to the emotion of happiness, it was possible to identify two changes during the facial emotion recognition task. Happiness is considered the only positive emotion among the six basic ones, being characterised by a feeling which the majority of people want to experience. The emotion of happiness not only involves the sensation of physical pleasure, but also other more global domains, such as excitement, achievement, relief and positive self-concept. In this sense, the recognition of happiness is adaptively important for tightening social and family bonds as well as for receiving gratitude, appreciation and motivation ${ }^{26,32}$.

The present study has found statistical difference between BPD and control groups for detection of happiness, with the BPD subjects being less sensitive and more hyper-reactive. Veague and Hooley ${ }^{36}$ also used dynamic faces with increasing emotional intensity and found that BPD subjects had a longer response time than the controls in the recognition of a happy face, despite the lack of difference between the groups regarding the total hits for this emotion.

Thome et al. ${ }^{37}$ also reported evidence that BPD patients rated the intensity of happiness in happy faces lower than controls. In this study, the lower rating of happiness was linked to a high-anger state. Such findings can be supported by the hypothesis that the emotion recognition of facial expressions may be a trait-dependent ability ${ }^{34}$.

It is still worth citing some studies which detected specific response biases for BPD regarding negative facial emotions, with highlight to the emotions of anger and fear ${ }^{30,36}$. In the present study, no type of specific response bias was found in the BPD group. The biases found in both groups were for the emotions of fear and surprise, which are common and clinically less significant 26,32 .

In view of the discussion raised about the facial emotion recognition task in BPD subjects and about the diversity of findings, one can observe that there still exists an area to be explored because of the methodological variability regarding the tasks of facial emotion recognition used by the different studies, which makes it difficult to compare and generalise the results ${ }^{38}$. In addition, further studies are necessary to assess the recognition of emotions in more complex and dynamic situations, that is, which are as close as the daily-life interactions, thus integrating more complex auditory, corporal and visual stimuli with mixed and ambiguous emotions $s^{4,10}$.

We emphasise that the present findings should be interpreted with caution as our sample consisted of women only and whose statistical power was not estimated, which does not allow direct generalisations to males and makes it difficult to determine whether the negative findings are due to the limited number of subjects. Another limitation is the fact that the use of different medications was not controlled in the outcome analyses, since some studies pointed to the influence of psychotropic substances on the recognition of emotional expressions ${ }^{39}$.

Regardless of the methodological gap and inconsistencies in this area, it is possible to state that individuals diagnosed with BPD in general tend to have deficits in the facial emotion recognition task compared to healthy ones ${ }^{8,33,40}$. In this sense, the results of the present study suggest that the BPD group had a poorer performance compared to the control group, a finding also corroborated by the literature.

\section{Disclosure}

The authors report no conflicts of interest. 


\section{Research support}

FAPESP (Fundação de Amparo à Pesquisa do Estado de São Paulo - Process no 2012/02260-7); CNPq (Conselho Nacional de Desenvolvimento Científico e Tecnológico - Productivity Grants: 301321/2016-7).

\section{References}

1. American Psychiatric Association (APA). Diagnostic and Statistical Manual of Mental Disorders, 4th edition, text revision. Washington, DC: APA; 2000.

2. American Psychiatric Association (APA). Diagnostic and Statistical Manual of Mental Disorders, 5th edition. Arlington: APA; 2013.

3. Herpertz SC, Zanarini M, Schulz CS, Siever L, Lieb K, Möller HJ; WFSBP Task Force on Personality Disorders; World Federation of Societies of Biological Psychiatry (WFSBP). World Federation of Societies of Biological Psychiatry (WFSBP) guidelines for biological treatment of personality disorders. World J Biol Psychiatry. 2007;8(4):212-44.

4. Domes G, Schulze L, Herpertz SC. Emotion recognition in borderline personality disorder-a review of the literature. J Pers Disord. 2009;23(1):6-19.

5. Mier D, Lis S, Esslinger C, Sauer C, Hagenhoff M, Ulferts J, et al. Neuronal correlates of social cognition in borderline personality disorder. Soc Cogn Affect Neurosci. 2013;8(5):531-7.

6. von Ceumern-Lindenstjerna IA, Brunner R, Parzer P, Frey M, Fiedler P, Resch F. [Perception of emotional facial expressions in female adolescents with borderline personality disorder]. Z Kinder Jugendpsychiatr Psychother. 2007;35(5):333-40.

7. Unoka Z, Fogd D, Füzy M, Csukly G. Misreading the facial signs: specific impairments and error patterns in recognition of facial emotions with negative valence in borderline personality disorder. Psychiatry Res. 2011;189(3):419-25.

8. Daros AR, Zakzanis KK, Ruocco AC. Facial emotion recognition in borderline personality disorder. Psychol Med. 2013;43(9):1953-63.

9. Leichsenring F, Leibing E, Kruse J, New AS, Leweke F. Borderline personality disorder. Lancet. 2011;377(9759):74-84.

10. Weniger G, Lange C, Sachsse U, Irle E. Reduced amygdala and hippocampus size in trauma-exposed women with borderline personality disorder and without posttraumatic stress disorder. J Psychiatry Neurosci. 2009;34(5):383-8.

11. First MB, Gibbon M, Spitzer RL, Williams JBW, Benjamin LS. Structured Clinical Interview for DSM-IV Axis II Personality Disorders (SCID-II). Washington, DC: American Psychiatric Press, Inc; 1997.

12. First MB, Spitzer RL, Gibbon M, Williams JBW. Structured Clinical Interview for DSM-IV Axis I Disorders, Clinician Version (SCID-CV). Washington, DC: American Psychiatric Press, Inc; 1996.

13. Beck AT, Epstein N, Brown G, Steer RA. An inventory for measuring clinical anxiety: psychometric properties. J Consult Clin Psychol. 1988;56(6):893-7.

14. Cunha JA. Manual da versão em português das Escalas Beck. São Paulo: Casa do Psicólogo; 2001.

15. Spitzer RL, Kroenke K, Williams JB. Validation and utility of a self-report version of PRIME-MD: the PHQ primary care study. Primary Care Evaluation of Mental Disorders. Patient Health Questionnaire. JAMA. 1999;282(18):1737-44.

16. de Lima Osório F, Vilela Mendes A, Crippa JA, Loureiro SR. Study of the discriminative validity of the PHQ-9 and PHQ-2 in a sample of Brazilian women in the context of primary health care. Perspect Psychiatr Care. 2009;45(3):216-27.

17. Hodgson R, Alwyn T, John B, Thom B, Smith A. The FAST Alcohol Screening Test. Alcohol. 2002;37(1):61-6.

18. Menezes-Gaya C, Zuardi AW, Loureiro SR, Crippa JA. Is the Fagerström Test for Nicotine Dependence a good instrument to assess tobacco use in patients with schizophrenia? Rev Bras Psiquiatr. 2009;31(3):289-90.
19. Heatherton TF, Kozlowski LT, Frecker RC, Fagerström KO. The Fagerström Test for Nicotine Dependence: a revision of the Fagerström Tolerance Questionnaire. Br J Addict. 1991;86(9):1119-27.

20. Carmo JT, Pueyo AA. A adaptação ao português do Fagerström test for nicotine dependence (FTND) para avaliar a dependência e tolerância à nicotina em fumantes brasileiros. Rev Bras Med. 2002;59(1/2):73-80.

21. Ekman P, Friesen WV. Pictures of facial affect. Palo Alto: Consulting Psychologists Press; 1976.

22. Arrais KC, Machado-de-Sousa JP, Trzesniak C, Santos Filho A, Ferrari MC, Osório FL, et al. Social anxiety disorder women easily recognize fearfull, sad and happy faces: the influence of gender. J Psychiatr Res. 2010;44(8):535-40.

23. Hosmer DW, Lemeshow S. Introduction to the logistic regression model. In: Hosmer DW, Lemeshow S. Applied logistic regression. New York: Wiley-Interscience Publication; 2000. p. 1-30.

24. Darwin C. The expression of the emotions in man and animals. London: John Murray; 1872.

25. Ekman PE, Richard JD. The nature of emotion: fundamental questions. New York: Oxford University Press; 1994.

26. Ekman P. Emotions revealed: recognizing faces and feelings to improve communication and emotional life. New York: Owl Books; 2004.

27. Elfenbein HA, Ambady N. On the universality and cultural specificity of emotion recognition: a meta-analysis. Psychol Bull. 2002;128(2):203-35.

28. Chen CH, Lennox B, Jacob R, Calder A, Lupson V, BisbrownChippendale R, et al. Explicit and implicit facial affect recognition in manic and depressed States of bipolar disorder: a functional magnetic resonance imaging study. Biol Psychiatry. 2006;59(1):31-9.

29. Kohler CG, Walker JB, Martin EA, Healey KM, Moberg PJ. Facial emotion perception in schizophrenia: a meta-analytic review. Schizophr Bull. 2010;36(5):1009-19.

30. Baer RA, Peters JR, Eisenlohr-Moul TA, Geiger PJ, Sauer SE. Emotionrelated cognitive processes in borderline personality disorder: a review of the empirical literature. Clin Psychol Rev. 2012;32(5):359-69.

31. Mitchell AE, Dickens GL, Picchioni MM. Facial emotion processing in borderline personality disorder: a systematic review and meta-analysis. Neuropsychol Rev. 2014;24(2):166-84.

32. Ekman PE, Friesen WV. Unmasking the face: A guide to recognizing emotions from facial clues. Cambridge: Ishk; 2003.

33. Ruocco AC, Amirthavasagam S, Choi-Kain LW, McMain SF. Neural correlates of negative emotionality in borderline personality disorder: an activation-likelihood-estimation meta-analysis. Biol Psychiatry. 2013;73(2):153-60.

34. Wagner AW, Linehan MM. Facial expression recognition ability among women with borderline personality disorder: implications for emotion regulation? J Pers Disord. 1999;13(4):329-44.

35. Gardner KJ, Qualter P, Stylianou M, Robinson AJ. Facial affect recognition in non-clinical adults with borderline personality features: the role of effortful control and rejection sensitivity. Pers Individ Dif. 2010;49:799804.

36. Veague HB, Hooley JM. Enhanced sensitivity and response bias for male anger in women with borderline personality disorder. Psychiatry Res. 2014;215(3):687-93.

37. Thome J, Liebke L, Bungert M, Schmahl C, Domes G, Bohus M, et al. Confidence in facial emotion recognition in borderline personality disorder. Personal Disord. 2016;7(2):159-68.

38. Freitas-Magalhães A. O Código de Ekman: o cérebro, a face e a emoção. Porto: Edições Universidade Fernando Pessoa; 2011.

39. Sabino ADV, Chagas MHN, Osório F. Effects of psychotropic drugs used in the treatment of anxiety disorders on the recognition of facial expressions of emotion: Critical analysis of literature. Neurosci Biobehav Rev. 2016;71:802-9.

40. Nicol K, Pope M, Hall J. Facial emotion recognition in borderline personality: an association, with childhood experience. Psychiatry Res. 2014;218(1-2):256-8. 